\title{
Impact of vitamin D supplementation on C-reactive protein; a systematic review and meta-analysis of randomized controlled trials
}

\author{
Mohsen Mazidi ${ }^{1,2}$, Peyman Rezaie ${ }^{3}$ and Hassan Vatanparast ${ }^{4^{*}}$
}

\begin{abstract}
Background: To evaluate the effect of vitamin D supplementation on C-reactive protein (CRP) through a systematic review and meta-analysis of randomized control trials (RCTs).

Methods: PubMed-Medline, SCOPUS, Google Scholar and Web of Science databases were searched (up until April 2016) to identify RCTs evaluating the impact of vitamin D supplementation on CRP. We used random effects models (using DerSimonian-Laird method) as well as the generic inverse variance methods for quantitative data synthesis. For sensitivity analysis, we applied leave-one-out approach. To examine the heterogeneity we used 12 index. Registration code: CRD42016036932.

Results: Among 1274 search items, 24 studies met the inclusion criteria in the final evaluation. Pooling the data together indicated a non-significant decrease in CRP level following administration of vitamin D (weighted mean difference [WMD] $-0.26(\mathrm{mg} / \mathrm{l}),\left(95 \% \mathrm{Cl}-0.75\right.$ to $0.22, \mathrm{~N}=26$ arms, heterogeneity $\left.p=0.042 ; \mathrm{I}^{2} 54.2 \%\right)$. The WMDs for IL6 was $0.67 \mathrm{pg} / \mathrm{ml}$, (95\% Cl 0.29 to $1.06, N=16$ arms, heterogeneity $\left.p=0.234 ; I^{2} 19.1 \%\right), 0.43 \mathrm{pg} / \mathrm{ml},(95 \% \mathrm{Cl} 0.08$ to $1.05, N=26$ arms, heterogeneity $\left.p=0.120 ; I^{2} 42.1 \%\right)$, for IL 10 , and $-0.11 \mathrm{pg} / \mathrm{ml},(95 \% \mathrm{Cl}-0.53$ to $0.30, N=12$ arms, heterogeneity $p=0.423 ; I^{2}$ 9.2\%) for TNF-a, $4.03 \mathrm{pg} / \mathrm{ml}$, (95\% Cl 3.50 to $4.57, N=3$ arms, heterogeneity $p=0.752$; $\left.I^{2} 8.1 \%\right)$ for adiponectin. Sensitivity analyses confirmed the robustness of the findings.

Conclusions: This study provided evidence that vitamin D supplementation had no impact on serum CRP, IL10, and TNF-a, while significantly increased serum IL6. We recommend RCTs with longer period of follow-up time (12 months) for future studies to provide explicit results.
\end{abstract}

Keywords: Meta-analysis, Vitamin D supplementation, C-reactive protein

\section{Background}

Historically, vitamin D is recognised for its important role for bone health. However, recent studies suggest extraskeletal effects of vitamin D through autocrine and paracrine systems. Low vitamin D concentrations are related with several diseases with inflammatory nature including rheumatoid arthritis, metabolic syndrome, type 2 diabetes, cardiovascular diseases, and some types of cancer [1]. Low vitamin $\mathrm{D}$ status is reported to to simulate mild acute

\footnotetext{
* Correspondence: vatan.h@usask.ca

${ }^{4}$ College of Pharmacy and Nutrition, University of Saskatchewan, Health

Sciences E-Wing, Clinic Place, Saskatoon, SK S7N 2Z4, Canada

Full list of author information is available at the end of the article
}

phase response in which casue elevated concentrations of $\mathrm{C}$-reactive protein (CRP), several hemostatic factors and different pro-inflammatory cytokines [2-4]. Studies suggest vitamin D suppelemnation may reduce circulating CRP levels and some other plasma inflammatory cytokines. However, inconsistent results are reported across completed randomized trials [5-7]. Cytokines such as interleukin 6 (IL-6), interleukin 10 (IL-10) and tumor necrosis factor- alpha (TNF-alpha) mediate the inflammatory response in human tehrfore they can serve as potential biomarkers of chronic inflammatory diseases [8-10]. The elevated circulating concentrations of pro-inflammatory cytokines, such as IL6, and hepatic 
acute phase proteins (e.g. CRP) is a common feature of such diseases with chronic inflammation [11, 12].

The potential effect of of vitamin D supplementation in decearsing chronic inflammation, if proven, is of public health interest given the disproportionate prevalence of vitamin D deficiency and insufficiency across the globe. A number of recent clinical trials have assessed vitamin D supplementation in different populations for its impact on circulating concentrations of several pro- and anti-inflammatory factors. However, such studies have had limitations such as small sample size, poor research design and subject traits (gender, ethnicity, age, etc.), and underpowered to achieve a comprehensive and reliable conclusion. Therfore there is substantial uncertainty about the net effect of vitamin D supplementation on CRP levels. Asystematic study which has addressed this issue dates back to 2014 inlcuding only a few studies [13]. Therefore, a comprehensive evalaution of evidence is needed to achieve an evidence-based conclusion. Hence, we aimed to address this uncertainty by systematically reviewing the literature, and meta-analysis of all trials, to explore the effects of vitamin D supplementation on CRP levels.

\section{Methods}

We conducted his systematic review based on the international referred Reporting Items for Systematic Reviews and Meta- Analyses (PRISMA) Guidelines [13, 14]. We registed our study in the International Prospective Register of Systematic Reviews, PROSPERO (registration no: CRD42016036932).

\section{Literature search strategy}

In litrature search we considred the effect of vitamin D supplementation on plasma CRP concentration as the primary exposure of interest. The secondary exposure was the effect of vitamin D supplementation on inflammatory and anti-inflammatory markers and cytokines. We considred multiple databases including PUBMED/ Medline, Cochrane Central Register of Controlled Trials (CCTR), Cochrane Database of Systematic Reviews (CDSR), Web of Science and Google Scholar, until April 2016 for litrature search. Weapplied relevant search terms to find a published and unpublished studies for our interested outcome (Additional file 1: Table S1). We conisdred no limitation on language.

\section{Selection criteria}

We selected published randomized control trials (RCTs) assessing the impact of vitamin $\mathrm{D}$ administration on the infmlamatory parametres. Criteria for selecting studies: (i) clinical trial with single-arm, parallel or cross-over designs; (ii) RCTs of participants received vitamin D supplement compared to control group (either no vitamin D or placebo); and (iii) studies with information on primary outcome at the baseline and the endpoint in each group or the net change values. Exclusion criteria were: (i) non-clinical trials including those with case-control, cross-sectional or cohort designs; and (ii) studies missing to report mean (or median) plasma concentrations of our measures of interest at the baseline and/or at the endpoint. We carried out the selection by removing the of duplicates followed by titles and abstracts screening by two reviewers. The agreement between the reviewers was conisderable (Kappa index: $0.87 ; p<0.001$ ). We resolved the disagreements at a meeting between reviewers prior to selected articles being retrieved.

\section{Data extraction and management:}

Two reviewers (MM, PR) retrieved the full text of studies the met the inclusion criteria, and screened to determine the eligibility. After assessment of methodological quality, the two reviewers extracted data onto a purpose-designed data extraction form. The same reviewers independently summarised the most significant results of each study $f$. We compared the summaries and any variations of ideas resolved through a discussion with the third reviewer (HV). Details information from selected RCTs is summarized in Table 1. An independent reviewer confirmed all data entries.

\section{Quality assessment}

We used the Cochrane criteria to assess potential bias [14].

\section{Data preparation for meta-analysis:}

According to Cochrane Handbook recommendations, the mean change from baseline in the level of variables of interest and standard deviation (SD) for both groups were collected and used to compute the effect size [15]. The following formula was used: $\mathrm{SD}=\mathrm{SEM} \times$ square root $(n)$, where $n$ is the number of subjects. We sued the GetData Graph Digitizer 2.24 [16] to extract the required data when theer were presented in graphs.

We applied random effects model (using the DerSimonian- Laird method) and the generic inverse variance method to take to account the heterogeneity of studies in terms of demographic characteristics of populations [17].A quantitaved assessment of Heterogeneity was conducted using $\mathrm{I}^{2}$ index, where values of $25 \%, 50 \%$, and $75 \%$ reflect low, medium and high heterogeneity, respectively. We expressed the effect sizes as the weighted mean differences (WMD) and 95\% confidence interval (CI). Sensetivity analysis was applied to assess the effct of each RCT on the overall effect size [18-20].

\section{Determining potential publication bias}

To determine potential publication bias we used Begg's rank correlation, and Egger's weighted regression tests 


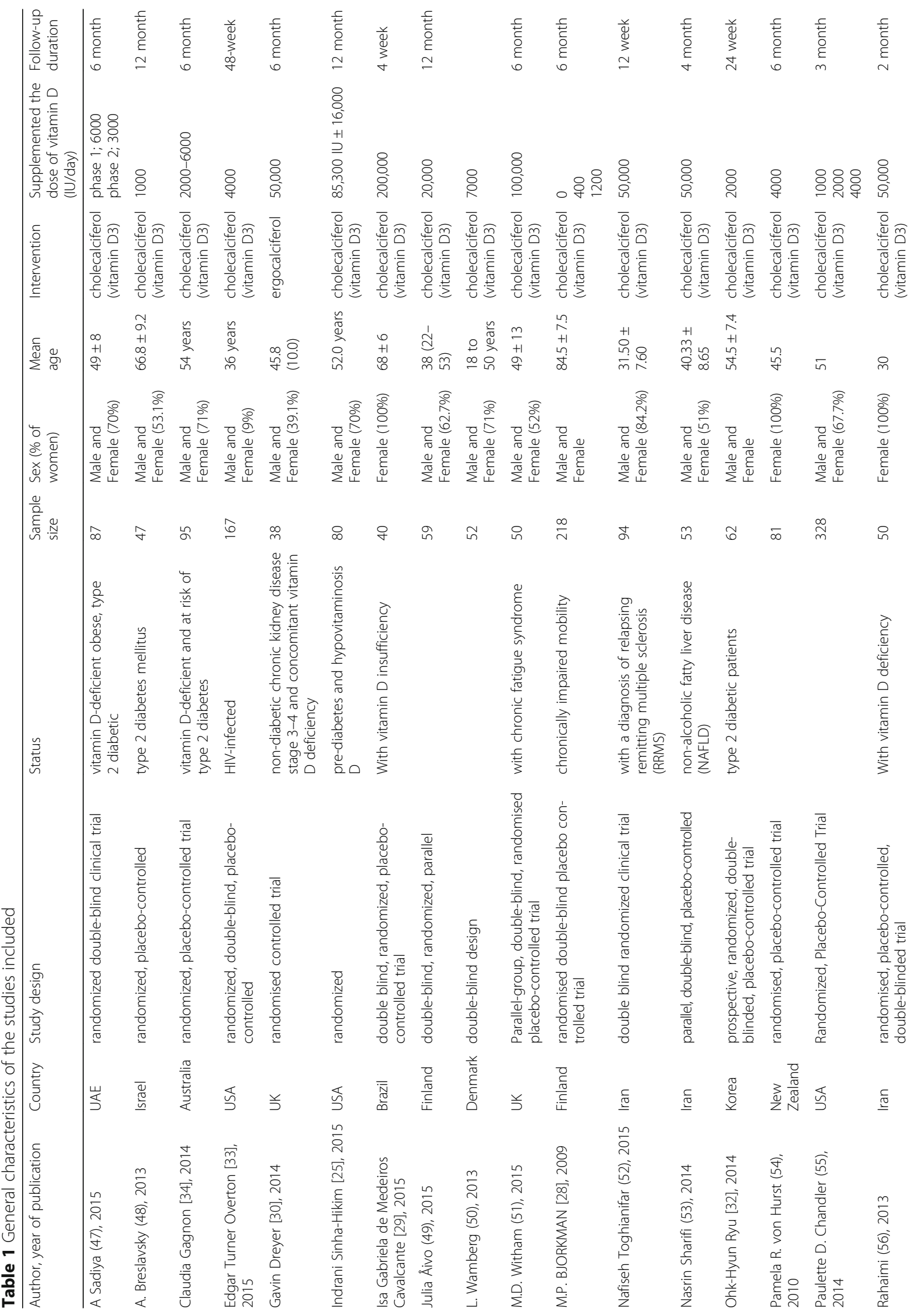




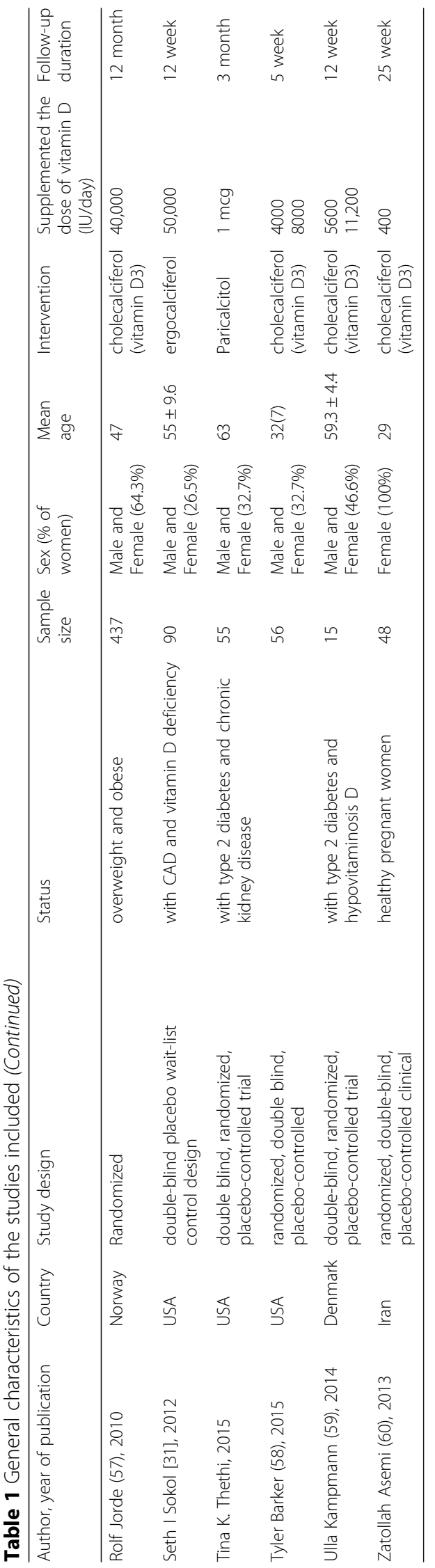




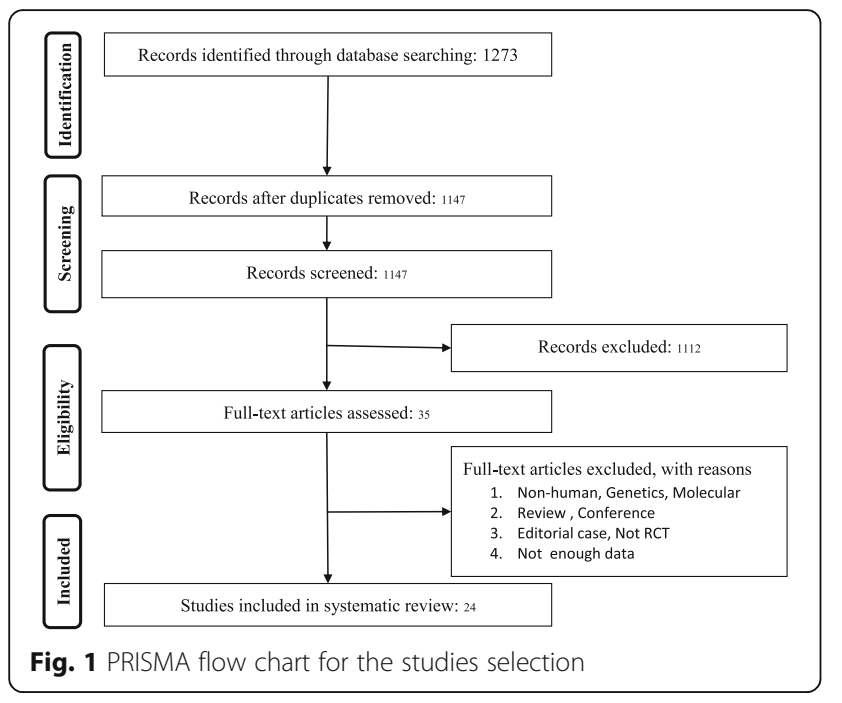

/The fill' and 'fail-safe N' and Duval \& Tweedie 'trim methods were applied to adjust for the potential effects of publication bias [21, 22]. The meta-analysis was preformed using Comprehensive Meta-Analysis (CMA) V3 software (Biostat, NJ) [23, 24].

\section{Results}

\section{Selection RCTs}

From searches in different search engines overall 1273 single citations recognized, of these, 126 were duplicates. From 1147 items, 35 left after assessment based on titles and abstracts, of which, 11 were not selected due to fact that: genetic, non-human studies, or molecular studies $(n=4)$; editorial or review articles $(n=3)$; incomplete data (2); Fig. 1. Consequently, 23 RCTs were used for pooling the data.

\section{Risk of bias assessment}

Results of assessment of bias revealed that some of the selected items recognized by the absence of information about the random sequence generation, blinding of outcome assessment and blinding of participants and study personnel, and allocation concealment. Though, nearly all of the assessed RCTs had a low risk of bias according to selective outcome reporting, with the exemption of two, which did not have sufficient material [25]. Details of the quality of bias assessment are presented in Additional file 1: Table S2.

\section{Characteristics of the studies}

A summary of the characteristics of the studies is presented in Table 1. The inclused studies have been published between 2009 and 2015 from 12 countries including the United States of America (six studies), Iran (four studies), Finland, Denmark, UK (two studies) and Norway, Australia, Korea, UAE, New Zealand, Israel, Brazil (one study), respectively. The number of study participants ranged from 15 to 437 among studies.Four studies included only women; while the proportion of women in other studies ranged from $9 \%$ to $84.1 \%$. The age of participants ranged from 18 to 92 years. The follow up duration from the baseline to endpoint across studies was from 4 weeks to one year. Various supplement regimens were assessed. Range of study population was from 15 [26] to 328 participants [27]. Twoenty one studies used cholecalciferol in a dosage range from $0 \mathrm{IU} / \mathrm{d}$ [28] to $200,000 \mathrm{IU} / \mathrm{d}$ [29]. In two of the studies, particciopants were summplemned with ergocalciferol at a dose of 50,000 IU at baseline for 26 [30] or 12 [31] weeks. In three studies, calcium supplements had also been administered in doses of 200 [32], 1000 [33], 1200 [34] $\mathrm{mg} / \mathrm{d}$, respectively.

\section{Pooled estimate of the impact of vitamin D supplementation on C-reactive protein}

The pooled estimate (weighted mean difference) of the effect of vitamin $\mathrm{D}$ supplementation on $\mathrm{C}$-reactive protein was $-0.26(\mathrm{mg} / \mathrm{l})$, (95\% CI -0.75 to $0.22, N=26$ arms, heterogeneity $p=0.042 ; \mathrm{I}^{2} 54.2 \%$ ) across all studies (Fig. 2). Further, we splited our data based on studies which followed their subjects $>6$ months and $6 \leq$, respectively. This sub-analsyes changed the results as follows, $-0.28(\mathrm{mg} / \mathrm{l}), \quad\left(95 \%\right.$ CI -0.44 to $\left.0.12, \mathrm{I}^{2} 22.1 \%\right)$ and -0.22 (mg/l), (95\% CI -0.33 to $0.11, \mathrm{I}^{2} 20.9 \%$ ) in more than six months and $\leq 6$ months accordingly. We have divided our data based on mean age of the participants $(>50$ and $50 \leq)$, pooled estimate for $>50$ group was $-0.75(\mathrm{mg} / \mathrm{l})$, (95\% CI -1.29 to $\left.-0.21, \mathrm{I}^{2} 32.9 \%\right)$ and $50 \leq-0.22(\mathrm{mg} / \mathrm{l})$, (95\% CI -0.36 to $-0.07, \mathrm{I}^{2} 25.9 \%$ ). In terms of the sex, we ran the analysis for studies which included just females $-0.34(\mathrm{mg} / \mathrm{l})$, (95\% CI -0.66 to $\left.0.23, \mathrm{I}^{2} 10.9 \%\right)$.

\section{Pooled estimate of the effect of vitamin D supplementation} on IL-6

The pooled estimate (weighted mean difference) of the impact of vitamin D supplementation on IL-6 was $0.67 \mathrm{pg} / \mathrm{ml},(95 \%$ CI 0.29 to $1.06, n=16$ arms, heterogeneity $p=0.234 ; \mathrm{I}^{2} 19.1 \%$ ) across all studies (Fig. 3).

\section{Pooled estimate of the effect of vitamin D supplementation on IL-10}

The pooled estimate (weighted mean difference) of the impact of vitamin D supplementation on IL-10 was $0.43 \mathrm{pg} / \mathrm{ml}$, (95\% CI -0.56 to $1.44, N=9$ arms, heterogeneity $p=0.120 ; \mathrm{I}^{2} 42.1 \%$ ) across all studies. 


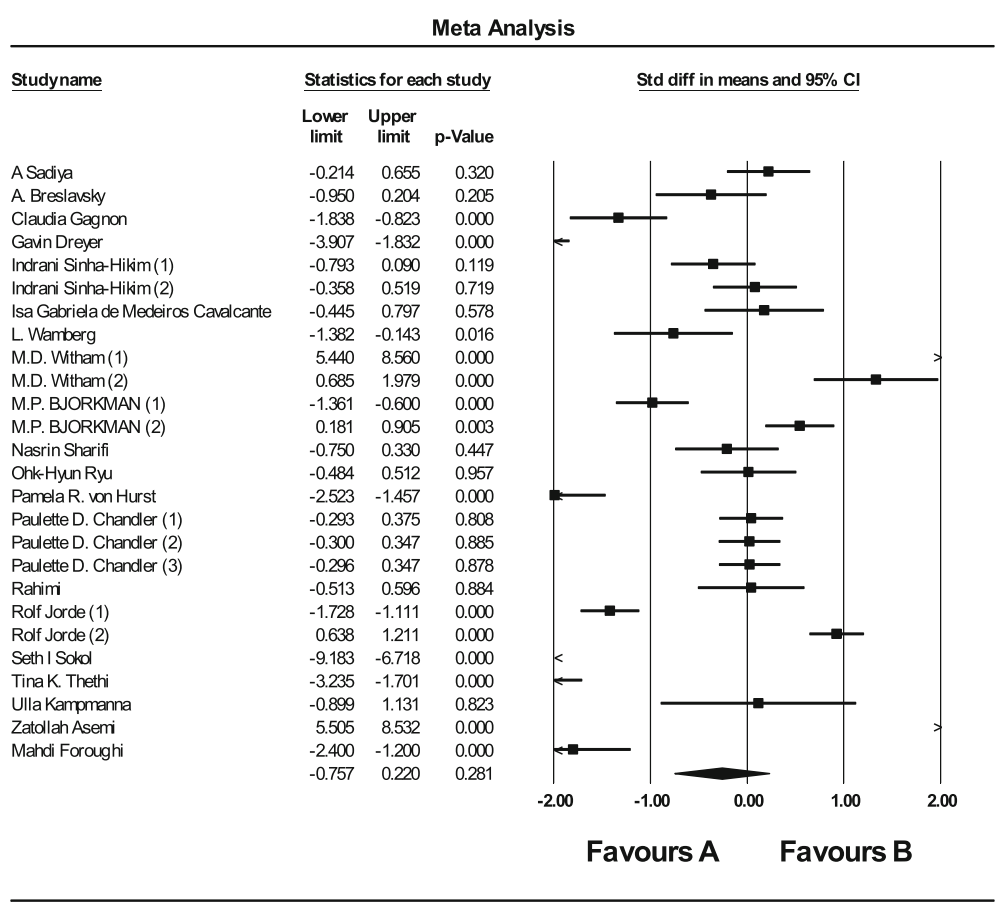

Meta Analysis

Fig. 2 Weighted mean difference of the effect of vitamin D supplementation on C-reactive protein

Pooled estimate of the effect of vitamin D supplementation on TNF-a

The pooled estimate (weighted mean difference) of the impact of vitamin D supplementation on TNF- $\alpha$ was $-0.11 \mathrm{pg} / \mathrm{ml}$, (95\% CI -0.53 to $0.30, N=12$ arms, heterogeneity $\left.p=0.423 ; \mathrm{I}^{2} 9.2 \%\right)$ across all studies.

\section{Pooled estimate of the effect of vitamin D supplementation} on adiponectin

The pooled estimate (weighted mean difference) of the impact of vitamin D supplementation on Adiponectin was $4.03 \mathrm{pg} / \mathrm{ml}$, (95\% CI 3.50 to $4.57, N=3$ arms, heterogeneity $p=0.752 ; \mathrm{I}^{2} 8.1 \%$ ) across all studies.

\section{Pooled estimate of the effect of vitamin D supplementation on ICAM-1}

The pooled estimate (weighted mean difference) of the impact of of vitamin D supplementation on ICAM-1 was $-0.79 \mathrm{pg} / \mathrm{ml}$, (95\% CI 1.33 to $0.26, N=4$ arms, heterogeneity $\left.p<0.001 ; \mathrm{I}^{2} 62.1 \%\right)$ across all studies.

Pooled estimate of the effect of vitamin D supplementation on IL-7

The pooled estimate (weighted mean difference) of the impact of vitamin D supplementation on IL-7 was $-2.32 \mathrm{pg} / \mathrm{ml}$, (95\% CI -4.32 to $-0.31, \mathrm{~N}=4$ arms, heterogeneity $\left.p=0.635 ; \mathrm{I}^{2} 7.9 \%\right)$ across all studies.
Pooled estimate of the effect of vitamin D supplementation on IL-2

The pooled estimate (weighted mean difference) of the impact of vitamin D supplementation on IL-2 was $-0.111 \mathrm{pg} / \mathrm{ml}$, (95\% CI -1.27 to $1.07, \mathrm{~N}=4$ arms, heterogeneity $\left.p=0.826 ; \mathrm{I}^{2} 6.3 \%\right)$ across all studies.

\section{Pooled estimate of the effect of vitamin D supplementation} on IL-4

The pooled estimate (weighted mean difference) of theimpact of vitamin D supplementation on IL-4 was $0.027 \mathrm{pg} / \mathrm{ml}$, (95\% CI -0.72 to $0.77, N=5$ arms, heterogeneity $\left.p=0.823 ; \mathrm{I}^{2} 4.9 \%\right)$ across all studies.

\section{Pooled estimate of the effect of vitamin D supplementation on IL-5}

The pooled estimate (weighted mean difference) of theimpact of vitamin D supplementation on IL-5 was $0.631 \mathrm{pg} / \mathrm{ml}$, (95\% CI -0.05 to $1.32, N=5$ arms, heterogeneity $\left.p=0.425 ; \mathrm{I}^{2} 5.8 \%\right)$ across all studies.

\section{Pooled estimate of the effect of vitamin D supplementation} on IL-12

The pooled estimate (weighted mean difference) of theimpact of vitamin D supplementation on IL-12 was $0.045 \mathrm{pg} / \mathrm{ml},(95 \% \mathrm{CI}-0.14$ to $0.23, \mathrm{~N}=5$ arms, heterogeneity $\left.p=0.358 ; \mathrm{I}^{2} 15.1 \%\right)$ across all studies. 


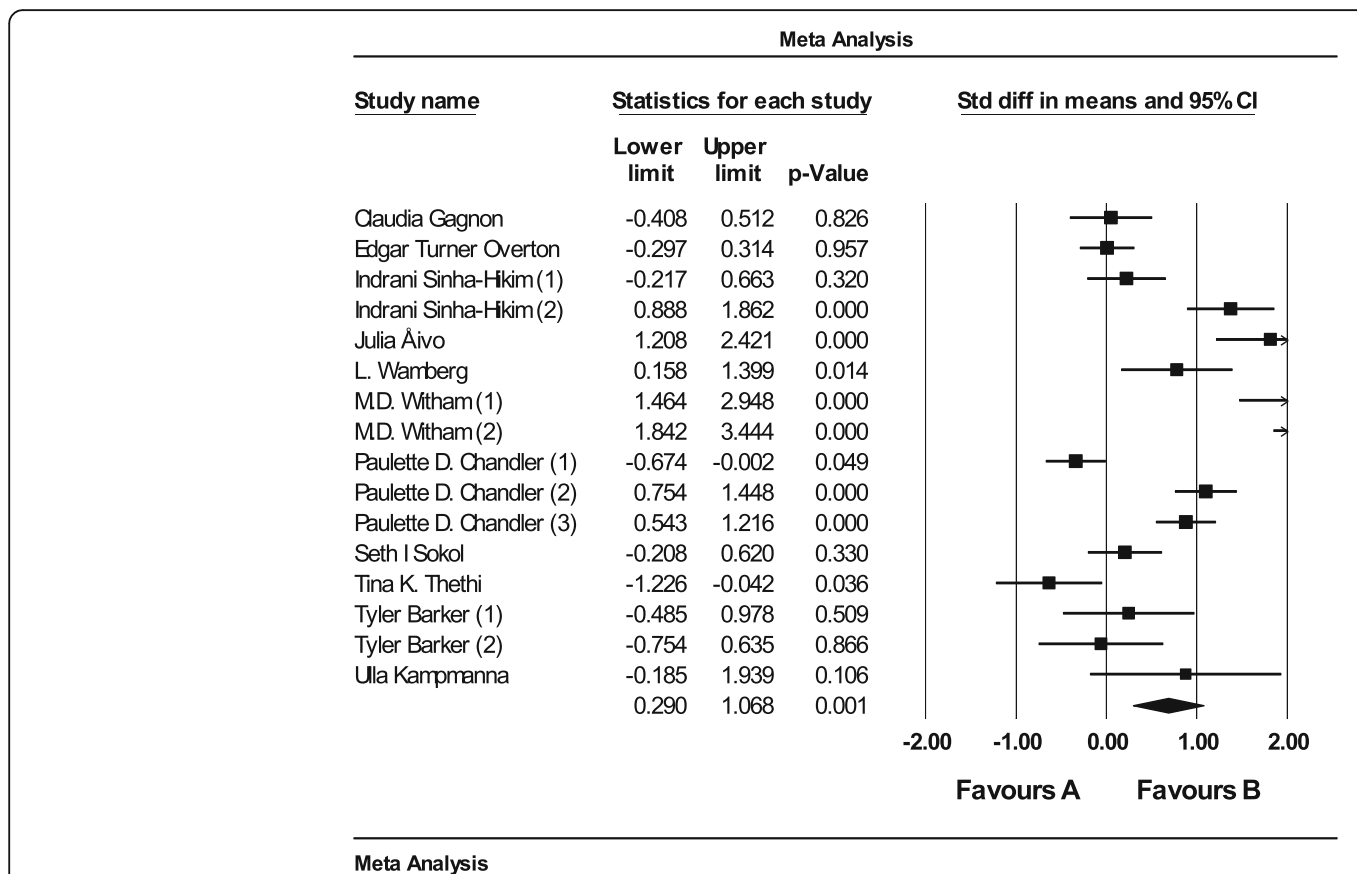

Fig. 3 Weighted mean difference of the effect of vitamin D supplementation on IL-6

\section{Pooled estimate of the effect of vitamin D supplementation} on IL-13

The pooled estimate (weighted mean difference) of the impact of vitamin D supplementation on IL-13 was $-0.15 \mathrm{pg} / \mathrm{ml}$, (95\% CI -0.78 to $0.48, \mathrm{~N}=5$ arms, heterogeneity $p=826 ; \mathrm{I}^{2} 3.7 \%$ ) across all studies.

\section{Sensitivity analysis}

Tthe pooled effect estimates remained similar across all studies in leave-one-out sensitivity analyses (Table 2).

\section{Publication bias}

The visual inspection of funnel plot asymmetry declared no potential publication bias for the comparison of CRP levels between vitamin D supplementation and placebo groups (Fig. 4). Moreover, the presence of publication bias was not suggested by Egger's linear regression (intercept $=2.12$, standard error $=2.68 ; 95 \% \mathrm{CI}=-3.41$, 7.66, $t=0.79, \mathrm{df}=24.00$, two-tailed $P=0.435)$ and Begg's rank correlation test (Kendall's Tau with continuity correction $=0.04, \mathrm{z}=0.28$, two-tailed $P$ value $=0.774$ ). After adjustment of effect size for potential publication bias using the 'trim and fill' correction, no potentially missing studies were imputed in funnel plots. Hence no difference in effect size than the initial estimate (WMD $-0.26(\mathrm{mg} / \mathrm{l}), 95 \% \mathrm{CI}-0.75$ to 0.22 ) (Fig. 5). The 'fail-safe N' test showed that 271 studies would be needed to bring the WMD down to a nonsignificant $(P>0.05)$ value.

\section{Discussion}

In the current meta-analysis of randomized trials, we investigated the impact of high-dose vitamin D supplementation on circulating inflammatory and anti-inflammatory indexes. We detected no effect of vitamin D supplementation on circulating CRP. However our analysis revealed that vitamin D supplementation significantly increased IL-6 level by $0.67(\mathrm{pg} / \mathrm{dl})$, while no significant effect was found on serum IL10 and TNF- $\alpha$.

From a theoretical point of view, there are several possible mechanisms that may explain vitamin D may affect serum CRP and IL-6. The physiological impact of vitamin $\mathrm{D}$ is not limited to the homeostasis of calcium and phosphate. For instance, vitamin D receptors (VDR) play role in the decreased activation of the pro-inflammatory transcription factor nuclear factor kappa B (NF-kB). This suggests that VDR has an intrinsic inhibitory role in inflammation $[35,36]$. One important target of vitamin $D$ is $N F-k B$, which is inhibited by vitamin $D$, and via $N F-\kappa \beta$ downstream release of the pro-inflammatory cytokines. $\mathrm{NF}-\mathrm{kB}$ activation participates in the endogenous induction of CRP. Accordingly, the activated NF- $\mathrm{kB}$ may increase the effects of an activator of transcription-3 (STAT3) [37]. Studies have shown the active form of vitamin D $(1,25$ dihydroxyvitamin D3 [1,25(OH)2D] inhibits NF-kB activation. This inhibatory effect is done by upregulating the inhibitor of NF- $\mathrm{kB}$ (IkB- $\alpha)$ and reducing IkB- $\alpha$ phosphorylation in lipopolysaccharide-stimulated murine macrophage cells as well as submissively sensitized human airway smooth muscle cells $[38,39]$. Thus, it may be 
Table 2 Sensitivity analysis across all studies

\begin{tabular}{|c|c|}
\hline Variables & Result of the leave-one-out sensitivity analyses \\
\hline \multicolumn{2}{|l|}{ C-reactive protein } \\
\hline Across all studies & $-0.26(\mathrm{mg} / \mathrm{l}),(95 \% \mathrm{Cl}-0.75$ to 0.22$)$ \\
\hline \multicolumn{2}{|l|}{ Interleukin-6 } \\
\hline Across all studies & $0.67(\mathrm{ng} / \mathrm{dl}),(95 \% \mathrm{Cl} 0.29$ to 1.06,$)$ \\
\hline \multicolumn{2}{|l|}{ Interleukin -10 } \\
\hline Across all studies & $0.43(\mathrm{ng} / \mathrm{dl}),(95 \% \mathrm{Cl}-0.56$ to 1.44$)$ \\
\hline \multicolumn{2}{|l|}{ TNF-a } \\
\hline Across all studies & $-0.11(\mathrm{ng} / \mathrm{dl}),(95 \% \mathrm{Cl}-0.53$ to 0.30$)$ \\
\hline \multicolumn{2}{|l|}{ Adiponectin } \\
\hline Across all studies & $4.03(\mathrm{pg} / \mathrm{ml}),(95 \% \mathrm{Cl} 3.50$ to 4.57$)$ \\
\hline \multicolumn{2}{|l|}{ ICAM-1 } \\
\hline Across all studies & $-0.79(\mathrm{pg} / \mathrm{ml}),(95 \% \mathrm{Cl} 1.33$ to 0.26$)$ \\
\hline \multicolumn{2}{|l|}{$\mid \mathrm{L}-7$} \\
\hline Across all studies & $-2.32(\mathrm{pg} / \mathrm{ml}),(95 \% \mathrm{Cl}-4.32$ to -0.31$)$ \\
\hline \multicolumn{2}{|l|}{$\mid \mathrm{L}-2$} \\
\hline Across all studies & $-0.111(\mathrm{pg} / \mathrm{ml}),(95 \% \mathrm{Cl}-1.27$ to 1.07$)$ \\
\hline \multicolumn{2}{|l|}{$\mid \mathrm{L}-4$} \\
\hline Across all studies & 0.027 (pg/ml), (95\% Cl -0.72 to 0.77$)$ \\
\hline \multicolumn{2}{|l|}{ IL-5 } \\
\hline Across all studies & $0.631(\mathrm{pg} / \mathrm{ml}),(95 \% \mathrm{Cl}-0.05$ to 1.32$)$ \\
\hline \multicolumn{2}{|l|}{ IL-12 } \\
\hline Across all studies & 0.045 (pg/ml), (95\% Cl -0.14 to 0.23$)$ \\
\hline \multicolumn{2}{|l|}{ IL-13 } \\
\hline Across all studies & $-0.15(\mathrm{pg} / \mathrm{ml}),(95 \% \mathrm{Cl}-0.78$ to 0.48$)$ \\
\hline $\mathrm{N}=$ Number & \\
\hline
\end{tabular}

hypothesised that vitamin D supplementation may suppress CRP via NF-kB and STAT3 signaling. Decreased parathyroid hormone $(\mathrm{PTH})$ production with vitamin $\mathrm{D}$ supplementation may also explain the effects of vitamin D on hs-CRP. Low PTH may lead to decreased production of inflammatory factors [40].

According to our results, existing studies report mixed results regarding the impact of vitamin D supplementation on CRP. The Framingham Offspring Study cohort reported no significant association was found between vitamin D and CRP $(n=1381)$ [41]. While, in a metaanalysis of 10 randomized controlled trials (Chen et al. 2014), investigating the effect of vitamin D supplimentation on CRP [13], vitamin D supplementation significantly decreased the circulating CRP level by $1.08 \mathrm{mg} / \mathrm{L}$ [13]. In addition,, a recent meta-analysis of randomized controlled trials indicated a favourable impact on markers inflammation with vitamin D treatment [40]. It has been stated that heterogeneity across the findings of the studies may be due to supplemental dose of vitamin $\mathrm{D}$, intervention durtaion and baseline hs-CRP level.
In the study by Forman et al.(2008) in a 1484 young women (aged 32 to 52 years)found that although vitamin D supplementation did not lower CRP specifically, it did lead to improvements in other inflammatory markers, for example IL-10 and TNF- $\alpha$ [42]. In addition, Ngo et al. studied 253 adults (aged 51 to 77 years) with mean CRP level of $3.6 \pm 4.0 \mathrm{mg} / \mathrm{mL}$ and reported serum vitamin D have significant converse association with CRP level [43]. This association was seen in 147 morbidly obese subjects with CRP levels ranged from 1.88 to $4.01 \mathrm{mg} / \mathrm{L}$ [44]. In one study impact of vitamin D supplementation on CRP and IL-6 was different [45]. The one-year vitamin D supplementation in overweight and obese participants resulted in reduced serum IL-6 concentrations, while serum CRP concentrations were significantly increased. The contradictory findings in these studies may be attributed to the length of the study, seasonal change or geographical location [45]. In a randomized control trial in patients with acute myocardial infarction, a short duration of treatment with vitamin D has significant impact on weakening the rise of CRP and IL-6 (but not TNF- $\alpha$ ) [46].

IL-6 is a multi-potential inflammatory cytokine that has a fundamental role in host defence including the immune responses, acute phase reactions and haematopoiesis [47]. Our analysis presented a positive association between vitamin D supplementation and circulating IL-6 levels. Our results may be influenced by seasonal differences in vitamin $\mathrm{D}$ level that cause changes in this increased levels of IL-6, IL-6-related signalling pathways, chronic diseases, congenital diseases, baseline IL- 6 level, age, sex of subjects and a supplemental dose of vitamin D. Hence, this finding needs to be reexamined in larger randomized trials specifically designed to investigate the relationship between inflammatory indexes and vitamin D.

Our study has some potential limitations. Internal validity of our results relies on the quality of individual studies as it is seen in all meta-analsyes. Several limitations can be named in this regard. Firstly, most studies in this meta-analysis had medium sample sizes. This may lead to overestimation of vitamin D supplementaion effects. Smaller trials might be methodologically less robust and more prone to report larger effect sizes [48, 49]. The number of available studies on this topic was rather small. Only four of the studies inlcuded in current meta-analyses were with the duration of 12 months. Among them, only one had a relatively large sample. Heterogeneity exist in doses of vitamin and health status of target population at the baseline. Further, most of the studies were conducted in clinical population rather than general healthy population. This may likely affect the baseline levels of vitamin D and the inflammatory markers. 


\section{Funnel Plot of Standard Error by Std diff in means}

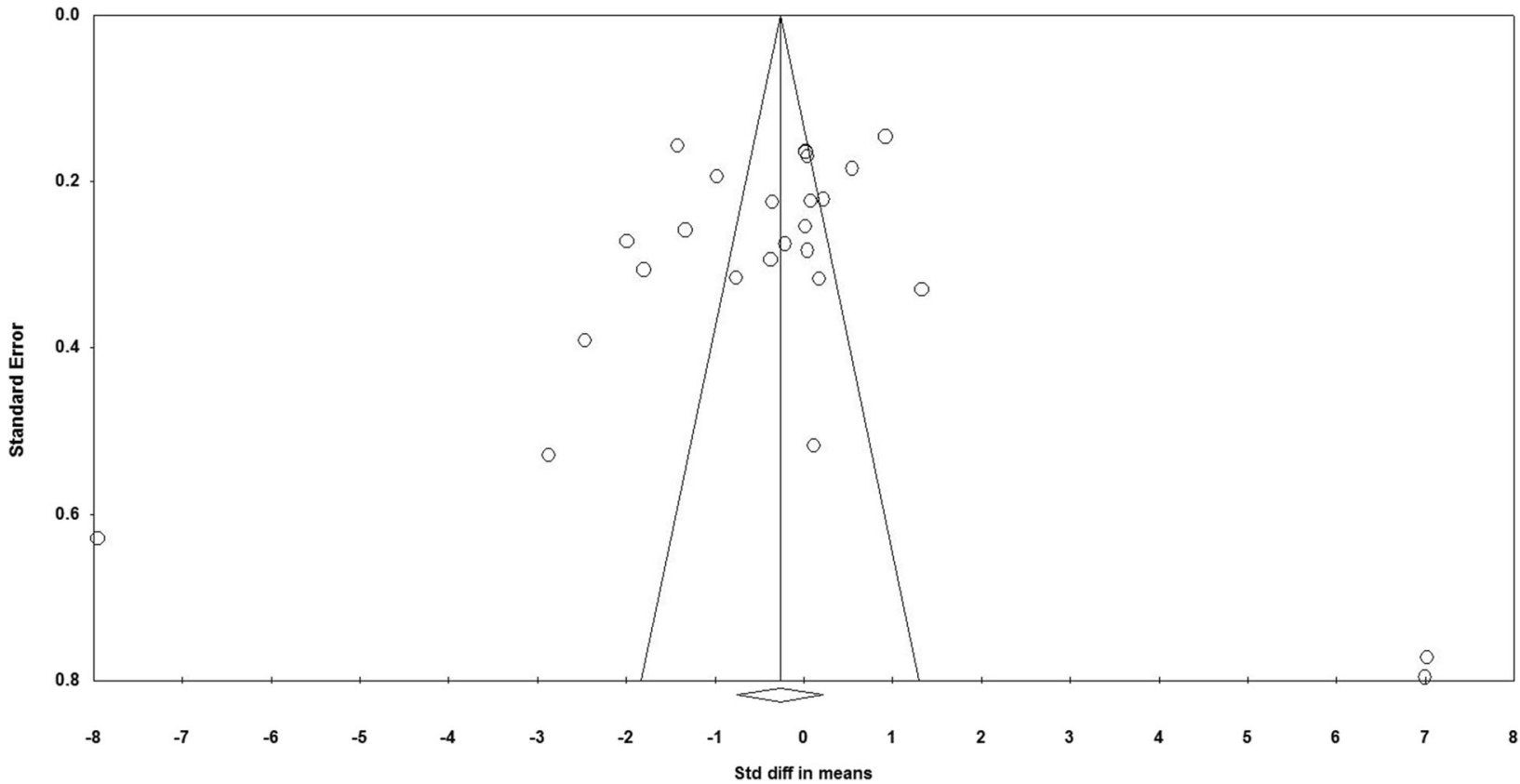

Fig. 4 Funnel plot of standard error by Std difference in means

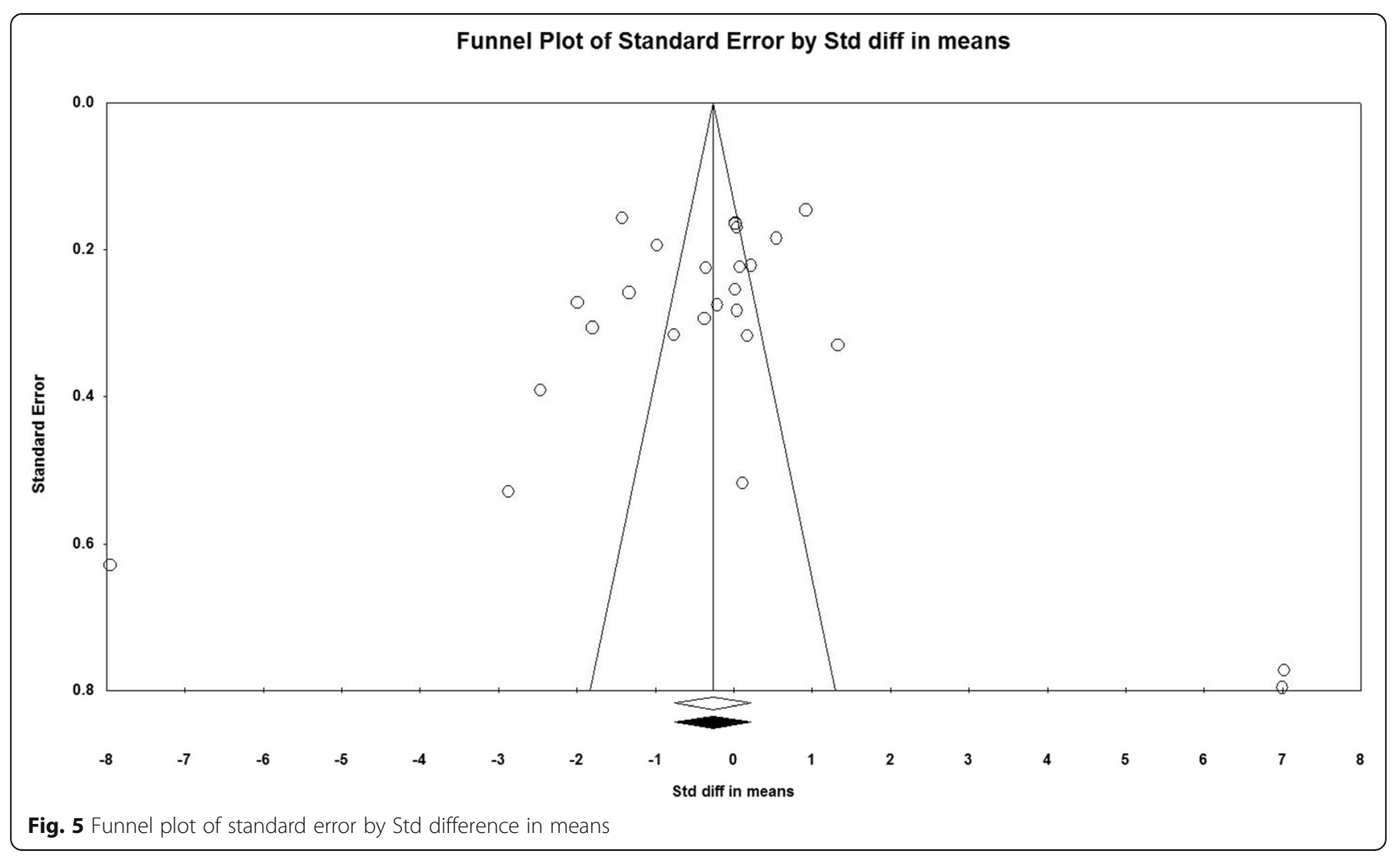




\section{Conclusion}

The current study revealed that vitamin D supplementation significantly increase level of IL6, while having no effect on CRP, IL10, and TNF- $\alpha$ concentration. RCTs with larger sample size and longer follow-up period (12 months) should be considered for future investigations to provide an unequivocal answer.

\section{Additional file}

Additional file 1: Table S1. Full search terms and strategy for the databases. Table S2. Quality of bias assessment of the included studies according to the Cochrane guidelines. (DOCX $26 \mathrm{~kb}$ )

\section{Abbreviations \\ CCTR: Cochrane Central Register of Controlled Trials; CDSR: Cochrane Database of Systematic Reviews; CDSR: randomized control trialsx; $\mathrm{Cl}$ : confidence interval; CRP: C-reactive protein; IL-10: Interleukin 10; IL- 6: Interleukin 6; NF-KB: Nuclear factor kappa B; PRISMA: Reporting Items for Systematic Reviews and Meta- Analyses; PROSPERO: International Prospective Register of Systematic Reviews; PTH: parathyroid hormone; SD: standard deviation; SEM: standard error of the mean; TNF-alpha: Tumour necrosis factor- alpha; VDR: Vitamin D receptors; WMD: weighted mean differences}

\section{Acknowledgements}

MM was supported by a TWAS studentship of the Chinese Academy of Sciences, during the preparation of this manuscript.

\section{Funding}

None.

\section{Availability of data and materials}

All data generated or analyzed during this study are included in this published article.

\section{Authors' contributions}

MM and HV designed the study. MM and PR searched databases, performed the selection of studies and wrote the manuscript.MM analysed the data; HV contributed to writing and critically appraising the manuscript and approved the final version. All authors reviewed and approved the final manuscript.

\section{Ethics approval and consent to participate}

Not applicable.

\section{Consent for publication}

Not applicable.

\section{Competing interests}

The authors declare that they have no competing interests.

\section{Publisher's Note}

Springer Nature remains neutral with regard to jurisdictional claims in published maps and institutional affiliations.

\footnotetext{
Author details

${ }^{1}$ Key State Laboratory of Molecular Developmental Biology, Institute of Genetics and Developmental Biology, Chinese Academy of Sciences, Chaoyang, Beijing, China. Institute of Genetics and Developmental Biology, International College, University of Chinese Academy of Science (IC-UCAS), West Beichen Road, Chaoyang, China. ${ }^{3}$ Biochemistry and Nutrition Research Center, School of Medicine, Mashhad University of Medical Science, Mashhad, Iran. ${ }^{4}$ College of Pharmacy and Nutrition, University of Saskatchewan, Health Sciences E-Wing, Clinic Place, Saskatoon, SK S7N 2Z4, Canada.
}

Received: 26 November 2016 Accepted: 7 December 2017

Published online: 02 February 2018

\section{References}

1. Holick MF, Vitamin D. deficiency. N Engl J Med. 2007;357(3):266-81.

2. Canning MO, Grotenhuis $\mathrm{K}$, de Wit H, Ruwhof C, Drexhage HA. 1-alpha, 25Dihydroxyvitamin D3 $(1,25(\mathrm{OH})(2) \mathrm{D}(3))$ hampers the maturation of fully active immature dendritic cells from monocytes. Eur J Endocrinol. 2001; 145(3):351-7.

3. McCarty MF. Secondary hyperparathyroidism promotes the acute phase response-a rationale for supplemental vitamin $D$ in prevention of vascular events in the elderly. Med Hypotheses. 2005;64(5):1022-6.

4. Zhu Y, Mahon BD, Froicu M, Cantorna MT. Calcium and 1a, 25dihydroxyvitamin D3 target the TNF-a pathway to suppress experimental inflammatory bowel disease. Eur J Immunol. 2005;35(1):217-24.

5. Gepner AD, Ramamurthy R, Krueger DC, Korcarz CE, Binkley N, Stein JHA. Prospective randomized controlled trial of the effects of vitamin $\mathrm{D}$ supplementation on cardiovascular disease risk. PLoS One. 2012;7(5):e36617.

6. Zhang Y, Leung DY, Richers BN, Liu Y, Remigio LK, Riches DW, et al. Vitamin $D$ inhibits monocyte/macrophage proinflammatory cytokine production by targeting MAPK phosphatase-1. J Immunol. 2012;188(5):2127-35.

7. Mazidi $M$, Karimi $E$, Rezaie $P$, Vatanparast $H$. The impact of vitamin $D$ supplement intake on vascular endothelial function; a systematic review and meta-analysis of randomized controlled trials. Food Nutr Res. 2017;61(1): 1273574.

8. Thorand B, Löwel H, Schneider A, Kolb H, Meisinger C, Fröhlich M, et al. Creactive protein as a predictor for incident diabetes mellitus among middleaged men: results from the MONICA Augsburg cohort study, 1984-1998. Arch Intern Med. 2003;163(1):93-9.

9. Pai JK, Pischon T, Ma J, Manson JE, Hankinson SE, Joshipura K, et al. Inflammatory markers and the risk of coronary heart disease in men and women. N Engl J Med. 2004;351(25):2599-610

10. Liu KD, Glidden DV, Eisner MD, Parsons PE, Ware LB, Wheeler A, et al. Predictive and pathogenetic value of plasma biomarkers for acute kidney injury in patients with acute lung injury. Crit Care Med. 2007:35(12):2755.

11. Multhoff $G$, Radons J. Radiation, inflammation, and immune responses in cancer. Front Oncol. 2012: 2(58.10):3389

12. Badawi A, Klip A, Haddad P, Cole D, Bailo BG, El-Sohemy A, et al. Type 2 diabetes mellitus and inflammation: prospects for biomarkers of risk and nutritional intervention. Diabetes Metab Syndr Obes. 2010;3:173-86.

13. Chen N, Wan Z, Han S-F, Li B-Y, Zhang Z-L, Qin L-Q. Effect of vitamin D supplementation on the level of circulating high-sensitivity $C$-reactive protein: a meta-analysis of randomized controlled trials. Nutrients. 2014:6(6):2206-16

14. Higgins JPT GSe. Cochrane Handbook for Systematic Reviews of Interventions. Version 5.0.2. London: The Cochrane Collaboration 2009.

15. Higgins J, Green S. Cochrane handbook for systematic reviews, version 5.0. 2 The Cochrane Collaboration. OpenURL; 2009.

16. Stylianou M, Nicolich MJ. Cumulative effects and threshold levels in air pollution mortality: data analysis of nine large US cities using the NMMAPS dataset. Environ Pollut. 2009;157(8-9):2216-23.

17. Sutton AJ, Abrams KR, Jones DR, Sheldon TA. F S. Methods for meta-analysis in medical research. West Sussex, UK: John Wiley \& Sons; 2000.

18. Ferretti G, Bacchetti T, Sahebkar A. Effect of statin therapy on paraoxonase-1 status: a systematic review and meta-analysis of 25 clinical trials. Prog Lipid Res. 2015;60:50-73.

19. Sahebkar A. Are curcuminoids effective C-reactive protein-lowering agents in clinical practice? Evidence from a meta-analysis. Phytotherapy research : PTR. 2014:28(5):633-42.

20. Sahebkar A, Serban MC, Mikhailidis DP, Toth PP, Muntner P, Ursoniu S, et al. Head-to-head comparison of statins versus fibrates in reducing plasma fibrinogen concentrations: a systematic review and meta-analysis. Pharmacol Res. 2016;103:236-52

21. Mazidi M, Kengne AP, Banach M; Lipid and Blood Pressure Meta-analysis Collaboration Group. Effects of coenzyme Q10 supplementation on plasma C-reactive protein concentrations: A systematic review and meta-analysis of randomized controlled trials. Pharmacol Res. 2017. https://doi.org/10.1016/j. phrs.2017.08.011. [Epub ahead of print].

22. Duval S, Tweedie R. Trim and fill: a simple funnel-plot-based method of testing and adjusting for publication bias in meta-analysis. Biometrics. 2000; 56(2):455-63. 
23. Borenstein M, Hedges L, Higgins J, Rothstein H. Comprehensive Metaanalysis (Vers. 2). Biostat. Inc: Englewood Cliffs, NJ; 2005.

24. Mazidi M, Karimi E, Rezaie P, Ferns GA. Effects of conjugated linoleic acid supplementation on serum C-reactive protein: A systematic review and meta-analysis of randomized controlled trials. Cardiovasc Ther. 2017. https:// doi.org/10.1111/1755-5922.12275.

25. Sinha-Hikim I, Duran P, Shen R, Lee M, Friedman TC, Davidson MB. Effect of long term vitamin D supplementation on biomarkers of inflammation in Latino and African-American subjects with pre-diabetes and hypovitaminosis D. Hormone and metabolic research= Hormon-und Stoffwechselforschung= Hormones et metabolisme. 2015;47(4):280.

26. Kampmann U, Mosekilde L, Juhl C, Moller N, Christensen B, Rejnmark L, et al. Effects of 12 weeks high dose vitamin D3 treatment on insulin sensitivity, beta cell function, and metabolic markers in patients with type 2 diabetes and vitamin D insufficiency - a double-blind, randomized, placebocontrolled trial. Metab Clin Exp. 2014;63(9):1115-24.

27. Chandler PD, Scott JB, Drake BF, Ng K, Manson JE, Rifai N, et al. Impact of vitamin $D$ supplementation on inflammatory markers in African Americans: results of a four-arm, randomized, placebo-controlled trial. Cancer prevention research (Philadelphia, Pa). 2014;7(2):218-25.

28. Bjorkman M, Sorva A, Tilvis R. C-reactive protein and fibrinogen of bedridden older patients in a six-month vitamin $D$ supplementation trial. JNHA-The J Nutr, Health Aging. 2009;13(5):435-9.

29. de Medeiros Cavalcante IG, Silva AS, Costa MJC, Persuhn DC, Issa Cl, de Luna Freire TL, et al. Effect of vitamin D3 supplementation and influence of Bsml polymorphism of the VDR gene of the inflammatory profile and oxidative stress in elderly women with vitamin D insufficiency: vitamin D3 megadose reduces inflammatory markers. Exp Gerontol. 2015;66:10-6.

30. Dreyer G, Tucker AT, Harwood SM, Pearse RM, Raftery MJ, Yaqoob MM. Ergocalciferol and microcirculatory function in chronic kidney disease and concomitant vitamin D deficiency: an exploratory, double blind, randomised controlled trial. PLoS One. 2014;9(7):e99461.

31. Sokol SI, Srinivas V, Crandall JP, Kim M, Tellides G, Lebastchi A, et al. The effects of vitamin $D$ repletion on endothelial function and inflammation in patients with coronary artery disease. Vasc Med. 2012;17(6):394-404.

32. Ryu O-H, Chung W, Lee S, Hong K-S, Choi M-G, Yoo HJ. The effect of highdose vitamin D supplementation on insulin resistance and arterial stiffness in patients with type 2 diabetes. Korean J Intern Med. 2014;29(5):620-9.

33. Overton $E$, Chan E, Brown T, editors. High-dose vitamin D and calcium attenuates bone loss with ART initiation: results from ACTG A5280. CROI 2014. Conference on Retroviruses and Opportunistic Infections Boston; 2014.

34. Gagnon C, Daly RM, Carpentier A, ZX L, Shore-Lorenti C, Sikaris K, et al. Effects of combined calcium and vitamin D supplementation on insulin secretion, insulin sensitivity and $\beta$-cell function in multi-ethnic vitamin Ddeficient adults at risk for type 2 diabetes: a pilot randomized, placebocontrolled trial. PLoS One. 2014;9(10):e109607.

35. Wu S, Liao AP, Xia Y, Li YC, Li J-D, Sartor RB, et al. Vitamin D receptor negatively regulates bacterial-stimulated NF-KB activity in intestine. Am J Pathol. 2010;177(2):686-97.

36. Chen Y, Zhang J, Ge X, Du J, Deb DK, Li YC, Vitamin D. Receptor inhibits nuclear factor $\mathrm{KB}$ activation by interacting with $\mathrm{K} B$ kinase $\beta$ protein. J Biol Chem. 2013;288(27):19450-8.

37. Agrawal A, Cha-Molstad H, Samols D, Kushner I. Overexpressed nuclear factor-KB can participate in endogenous $C$-reactive protein induction, and enhances the effects of $C / E B P \beta$ and signal transducer and activator of transcription-3. Immunology. 2003;108(4):539-47.

38. Cohen-Lahav M, Shany S, Tobvin D, Chaimovitz C, Douvdevani A, Vitamin D. Decreases NFKB activity by increasing IKBa levels. Nephrology dialysis. Transplantation. 2006;21(4):889-97.

39. Song Y, Hong J, Liu D, Lin Q, Lai G. 1, 25-Dihydroxyvitamin D3 inhibits nuclear factor kappa B activation by stabilizing inhibitor IKBa via mRNA stability and reduced phosphorylation in passively sensitized human airway smooth muscle cells. Scand J Immunol. 2013;77(2):109-16.

40. Serban M-C, Sahebkar A, Michos ED, Barter PJ, Muntner P, Toth PP, et al. Vitamin $D$ influences biomarkers of oxidative stress and serum high sensitivity C-reactive protein concentrations: a systematic review and metaanalysis of randomized controlled trials. Am Heart Assoc; 2016.

41. Shea MK, Booth SL, Massaro JM, Jacques PF, D'Agostino RB, DawsonHughes B, et al. Vitamin K and vitamin D status: associations with inflammatory markers in the Framingham offspring study. Am J Epidemiol. 2008;167(3):313-20.
42. Forman JP, Curhan GC, Taylor EN. Plasma 25-hydroxyvitamin D levels and risk of incident hypertension among young women. Hypertension. 2008; 52(5):828-32.

43. Ngo DT, Sverdlov AL, McNeil JJ, Horowitz JD. Does vitamin D modulate asymmetric dimethylarginine and C-reactive protein concentrations? Am J Med. 2010;123(4):335-41.

44. Bellia A, Garcovich C, D'Adamo M, Lombardo M, Tesauro M, Donadel G, et al. Serum 25-hydroxyvitamin D levels are inversely associated with systemic inflammation in severe obese subjects. Intern Emerg Med. 2013;8(1):33-40.

45. Beilfuss J, Berg V, Sneve M, Jorde R, Kamycheva E. Effects of a 1-year supplementation with cholecalciferol on interleukin-6, tumor necrosis factor-alpha and insulin resistance in overweight and obese subjects. Cytokine. 2012;60(3):870-4.

46. Arnson Y, Itzhaky D, Mosseri M, Barak V, Tzur B, Agmon-Levin N, et al. Vitamin D inflammatory cytokines and coronary events: a comprehensive review. Clin Rev Allergy Immunol. 2013;45(2):236-47.

47. Hubackova S, Krejcikova K, Bartek J, Hodny Z. Interleukin 6 signaling regulates promyelocytic leukemia protein gene expression in human normal and cancer cells. J Biol Chem. 2012;287(32):26702-14.

48. Nuesch E, Trelle S, Reichenbach S, Rutjes AW, Tschannen B, Altman DG, et al. Small study effects in meta-analyses of osteoarthritis trials: metaepidemiological study. BMJ (Clinical research ed). 2010;341:c3515.

49. Sterne JA, Gavaghan D, Egger M. Publication and related bias in metaanalysis: power of statistical tests and prevalence in the literature. J Clin Epidemiol. 2000;53(11):1119-29.

\section{Submit your next manuscript to BioMed Central and we will help you at every step:}

- We accept pre-submission inquiries

- Our selector tool helps you to find the most relevant journal

- We provide round the clock customer support

- Convenient online submission

- Thorough peer review

- Inclusion in PubMed and all major indexing services

- Maximum visibility for your research

Submit your manuscript at www.biomedcentral.com/submit
C Biomed Central 